\title{
Tissue P53-Induced Glycolysis and Apoptosis Regulator (TIGAR) is Associated with Oxidative Stress in Benign and Malignant Colorectal Lesions
}

\author{
Maha Ali ${ }^{1}$, Ragaa H.M. Salama ${ }^{1}$, Asmaa A. Kamal ${ }^{1}$, Heba E El-Deek ${ }^{2}$, AbdelMotaleb AA ${ }^{3}$, Abeer S. Abd-El- \\ Rehim $^{4}$, Elham A. Hassan ${ }^{4}$, Alsanory AA ${ }^{5}$, Mahmoud M. Saad ${ }^{6}$, Marwa A. Dahpy*1,7 \\ ${ }^{1}$ Department of Medical Biochemistry and Molecular Biology, ${ }^{2}$ Department of Pathology, ${ }^{3}$ Department of Surgery, ${ }^{4}$ \\ Department of tropical medicine, ${ }^{5}$ Nuclear Medicine Unit, South Egypt Cancer Institute, ${ }^{6}$ Department of Orthopedic, \\ Faculty of Medicine, Assiut University, Assiut, Egypt ${ }^{7}$ Department of Medical Biochemistry and Molecular Biology, \\ Armed forces collage of Medicine (AFCM), Cairo, Egypt. \\ *Correspondence: Dr/: Marwa A. Dahpy E-mail: marwadahpy@aun.edu.eg, marwadahpy@yahoo.com, \\ Mobile:00201121188159.
}

\begin{abstract}
Background: Colorectal cancer (CRC) is the fourth leading cause of cancer-mortality worldwide. Tissue p53-induced glycolysis and apoptosis regulator gene (TIGAR) has an important role in cellular glycolysis and acts as an oncogene. Objectives: We aimed to investigate the diagnostic utility of TIGAR in both CRC and benign bowel deceases.

Methods: One-hundred-eighty tissue samples were recruited and classified into 3 groups: group (1) 60 CRC samples from the tumor mass of colorectal cancer patients, group (2), 60 non-neoplastic colorectal tissue samples and group (3), 60 benign bowel lesions samples (ulcerative-colitis, Chron's disease, adenoma, and familial adenomatous polyposis). The expressions of tissue mRNA and protein levels of TIGAR were determined. Levels of malondialdehyde and reduced glutathione were also measured.

Results: Our results showed upregulated expressions of TIGAR gene and protein levels in CRC tissues and benign colonic lesions compared to non-tumor tissues $(\mathrm{p}<0.0001)$. Their levels were higher in inflammatory bowel diseases compared to non-inflammatory benign lesions. There were significant relations among TIGAR expression, protein levels, TNM staging, and the presence of metastasis $(\mathrm{p}<0.0001)$. ROC curve analysis showed that TIGAR mRNA expression and its protein can discriminate between CRC and benign lesions and between benign bowel disease and controls.
\end{abstract}

Conclusions: To the best of our knowledge this is the first study to assess the level of TIGAR in different benign bowel diseases. TIGAR might be involved in the pathogenesis of benign and malignant bowel diseases and could be a potential biomarker for diagnosis.

Keywords: Tissue p53-induced glycolysis and apoptosis regulator gene (TIGAR), Benign colonic lesions, Colorectal cancer.

\section{INTRODUCTION}

In Egypt, CRC constitutes $4.2 \%$ of all cancers ${ }^{(1)}$, and it has a relatively high young onset ${ }^{(2)}$. CRC is known as a "silent disease," as many people do not have complaints and mostly diagnosed at an advanced stage ${ }^{(3)}$. Despite recent advances in diagnosis and management of CRC, the radical cure still a challenge work because of complexity of CRC, beside the drug resistance, and the recurrence and/or metastasis after surgical intervention (4). People with a family history of CRC have the risk to develop the disease ${ }^{(5)}$, the most common hereditary forms are familial adenomatous polyposis (FAP) and lynch syndrome ${ }^{(6,7)}$. Inflammatory bowel diseases (IBD) patients such as ulcerative colitis and Crohn's disease, are also at high risk of developing the CRC, especially with increasing duration and extent of the disease ${ }^{(\mathbf{8})}$.

Tissue P53-induced glycolysis and apoptosis regulator $(T I G A R)$ has the function of fructose 2,6bisphosphatase, decreases the levels of fructose 2,6bisphophate, thus blocks glycolysis and increasing pentose phosphate pathway (PPP) flux ${ }^{(9)}$. Therefore, TIGAR decreases intracellular levels of reactive oxygen species (ROS)through the PPP shunt by the generation of NADPH ${ }^{(10)}$. PPP provides NADPH and ribose necessary for the synthesis and repair of DNA that play an essential role in tumor development and cellular survival ${ }^{(11)}$.

TIGAR also interact with hexokinase 2 as it translocates to the mitochondria, this help reducing ROS levels by contributing in mitochondrial membrane potential regulation $^{(12)}$.

Many studies suggested that as TIGAR expression is up-regulated and uncoupled from p53, which suggests its role as an oncogene that help cellular proliferation, tumorigenesis and cancer progression ${ }^{(\mathbf{1 3})}$.

A high expression level of TIGAR was observed in several cancers such as glioblastoma (14). invasive breast cancer ${ }^{(15)}$, hepatocellular carcinoma ${ }^{(16)}$, and intestinal cancers ${ }^{(11)}$. The role of TIGAR in benign bowel diseases and CRC so far still unclear. In this study we aimed to evaluate the diagnostic value of TIGAR in CRC patients and in patients with benign bowel diseases, which is considered as high-risk groups or precancerous conditions. Also, we aimed to investigate how its expression correlates with the cancer pathology and the clinicopathological staging. In addition, studying its relationship with malondialdehyde (MDA) and reduced 
glutathione (GSH) as major contributors in tumorigenesis. This may help establishing a new promising insight for inhibition of CRC development in the high-risk patients.

\section{PATIENTS AND METHODS}

\section{Patients' characteristics:}

This is a case-control study carried out on 120 patients, who were admitted to the general surgery and gastroenterology departments at Assiut University Hospitals. The calculation of sample size was carried out by G*Power 3 software.

\section{Ethical approval:}

We had a written consent from each participant in the study for the use of their tissue specimens after surgical removal. World Medical Association's Ethical Code for human research (Helsinki Declaration) was followed and the study was approved by the Ethical Committee of Assiut University, Egypt (IRB no.17200174).

Inclusion criteria: Adult patients admitted to the general surgery department, Assiut University Hospitals, aged 30 to 60 years old who confirmed to have stage II or III CRC by histopathology according to TNM Staging System and patients who admitted to gastroenterology department, Assiut University Hospitals for diagnostic or follow up by colonoscopy.

Exclusion criteria: Any patient with a history of CRC and/or patients whom post-surgically treated with chemotherapy or other chronic diseases were excluded from this study.

All participants in the current study were subjected to the following: Filling a questionnaire about age, sex, smoking status, dietary habit, and any hormonal treatment together with any other performed investigations. Presenting history (including symptoms of abdominal pain, constipation, or the complaint leading to seeking clinical advice). Family history of CRC, familial polyposis, or inflammatory bowel disease, and their medical and dietary histories (frequency of red meat, fruits, and vegetable intake).

\section{Tissue collection:}

One hundred eighty tissue samples classified into 3 groups: Group (1) includes 60 CRC samples from the tumor mass of colorectal cancer patients. Group (2) includes 60 non-neoplastic colorectal tissue samples, $1 \mathrm{~cm}$ from the tumor tissues, considered as controls. Group (3) includes 60 high risk group patients include those with benign bowel lesions, classified as follow: 32 Ulcerative colitis, 4 patients with Crohn's disease, 8 adenomas and 16 familial adenomatous polyposis.

\section{Tissue homogenates preparation:}

Immediately after surgical excision the samples were taken, washed with saline and snap frozen in liquid nitrogen then stored at $-80^{\circ} \mathrm{C}$. At the start of laboratory work, samples were washed with pre-cooling PBS buffer $(\mathrm{pH}=7.4)$, weighed then minced and homogenized in
PBS (each 1gram tissue pieces homogenized with a glass homogenizer in $9 \mathrm{~mL}$ PBS). All steps were performed on ice. Thermo Scientific Gene JET RNA purification kit (Catalog \#K0731) was used to extract RNA from tissue homogenate.

\section{Bioinformatics analysis:}

We searched Human protein Atlas, and Gene Card databases to choose TIGAR gene (ENSG00000078237), and to confirm the gene ontology and its expression in cancer tissues.

\section{Expression of tissue TIGAR by Real-Time Quantitative PCR:}

Purified RNA concentration was measured using Nanodrop ${ }^{\circledR}$ (Epoch Microplate Spectrophotometer, Biotek, VA, USA). Then RNA samples were stored at $80{ }^{\circ} \mathrm{C}$ until use.

The Thermo Scientific Revert Aid First Strand cDNA synthesis kit (Catalog \#K1622) was used to obtain complementary DNA (cDNA). Complementary DNA was diluted 1:5 with PCR grade water then stored at $20^{\circ} \mathrm{C}$ until qPCR. Performance of quantitative polymerase chain reaction (qPCR) was done (using Maxima SYBR Green qPCR master mix (2X) kit (Thermo Scientific Catalog \#K0251). We used the 7500 Fast Real-time PCR machine (Applied Biosystems, Germany) for RT-qPCR with GADPH as the internal control. The 5'-3' primers sequences for TIGAR were forward: CTCCAGTGATCTCATGAG and reverse: AGACACTGGCTGCTAATC. Housekeeping gene GADPH forward: ACAGTCAGCCGCATCTTCTT and GADPH reverse: ACCAGCTTCCCATTCTCAGC. Primers sequences were according to published (18) and primer 3 algorism. The PCR cycling conditions after optimization were as follows: initial denaturation step at $95^{\circ} \mathrm{C}$ for $30 \mathrm{sec}$, followed by 40 cycles of $95^{\circ} \mathrm{C}$ for 15 sec then $60^{\circ} \mathrm{C}$ for $60 \mathrm{sec}$.

\section{Enzyme-linked immunosorbent assay (ELISA):}

Tissue homogenates were centrifuged for 5minutes at $5000 \times$ g. Biuret Colorimetric Assay kit was used to estimate the total protein levels in tissue supernatant (catalog No: E-BC-K165-S Elabscience Biotechnology Inc.). TIGAR protein level in tissue supernatant was determined by ELISA Kit (catalog No. \#: SG-16115), supplied by Glory Science Co., Ltd.

\section{Colorimetric assay:}

Reduced glutathione (GSH) and MDA were assayed in the studied tissues by colorimetric kit (catalog no. GR2511and MD 2529 respectively) supplied by Biodiagnostics, Egypt.

\section{Statistical analysis:}

Statistical package for social science (SPSS) version 20.0 and Prism version 5.0 were used for statistical analyses of the data. Findings were presented in tabular and/or diagrammatic formats. Graphics performed using 
Prism version 5.0, whereas the cutoff point, sensitivity, and specificity made by using the MedCalc. program. All data were expressed as mean \pm SEM. Student t-test and Mann-Whitney was used for normally distributed data and kurtotic, skewed data respectively. The Kruskal-Wallis analysis of variance used for analysis of significance of the difference among the groups. Differences considered significant at $\mathrm{p} \leq 0.05$.

\section{RESULTS}

\section{- Demographic data of cancer and benign groups}

The present study included 28 males and 32 females in the CRC group, however, in benign group 37 males and 23 females with no significant difference. The mean age of the cancer patients was $41.97 \pm 1.61$ (range 23-60) years while that of benign group was $40.23 \pm 1.27$ (range 25-60) years also, with no significant difference.

- Assessment of TIGAR mRNA and protein levels:
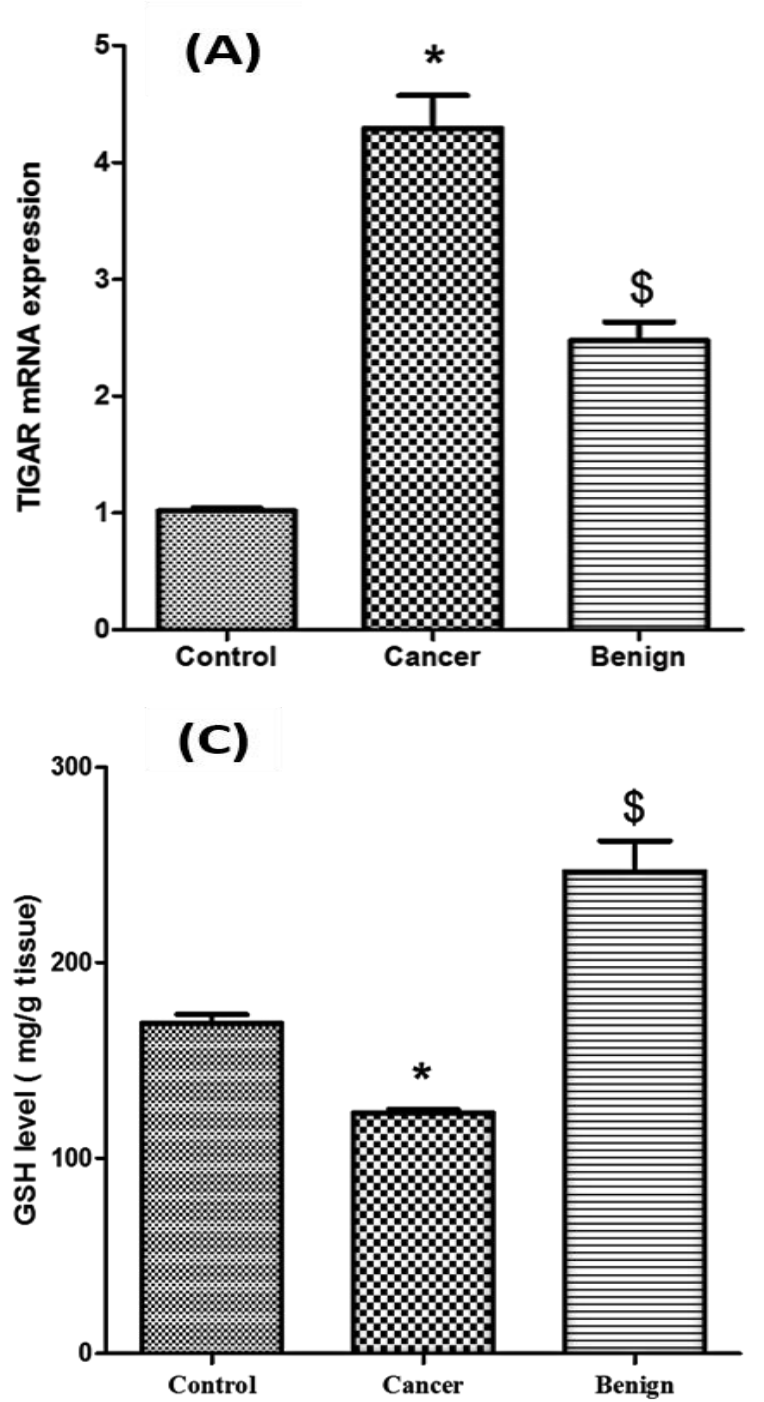

The results of the present work showed that TIGAR mRNA expression level was significantly upregulated in CRC group compared to benign group and noncancerous safety margin of the tumor (control group). Also, they were higher in benign lesion compared to control group (Figure 1A). There are also significant increase in TIGAR protein level in the CRC group compared to benign lesions, and in benign lesions group in comparison with control group (Figure 1B).

\section{- $\quad$ Assessment of oxidative stress markers:}

Levels of reduced glutathione (GSH) were significantly decreased in CRC group in comparison with benign and control groups and while, significantly increased in benign lesions group compared to other groups (Figure 1C). Oppositely, malondialdhyde (MDA) showed significant high levels in CRC and benign lesions compared to control group. Its level in CRC was also higher than that in benign lesions (Figure 1D).

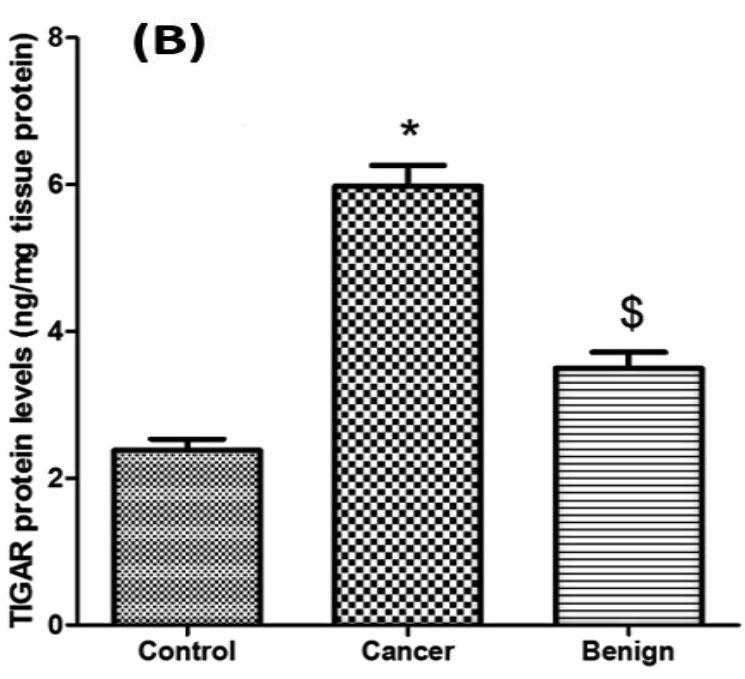

(D)

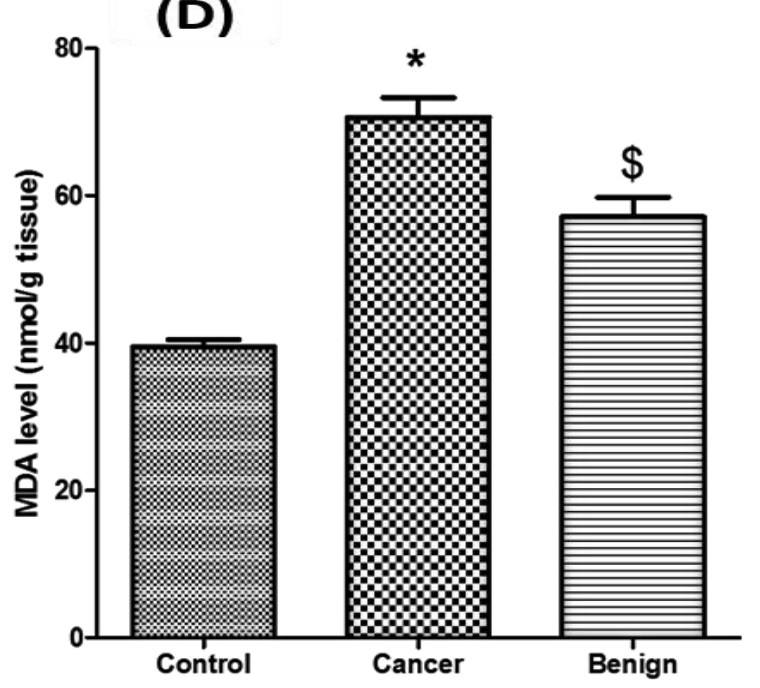

Figure (1): Tissue levels of the studied markers. (A) Relative quantitative expression of mRNA level of TIGAR in colonic tissue of control, cancer, and benign groups. Gene expression level was normalized to GAPDH, n=60. (B) Quantitative expression of protein level of TIGAR in colonic tissue of control, cancer, and benign groups. $\mathrm{n}=60$. (C) GSH levels in control, cancer and benign groups. (D) MDA levels in control, cancer, and benign groups. Data are expressed as means \pm SEM. P value is considered significant when < 0.05. *: cancer vs control and benign. \$: benign vs control. 
- Relationship analysis between measured biochemical markers and clinical findings of the studied groups: In this study, the high TIGAR expression and protein level together with high tissue MDA levels, were significantly associated with TNM staging, and positive lymph node metastasis ( $\mathrm{p}=0.0001$ each). TIGAR protein levels were significantly associated with site of tumor $(\mathrm{p}=0.03)$, the highest level was in colon. There was also significant association between TIGAR protein levels and tumor pathology $(\mathrm{p}=0.002)$. The signet ring adenocarcinoma showed the highest values (Table 1). Also, there were significantly higher TIGAR gene expression, protein levels and lower GSH levels in benign inflammatory bowel benign lesions $(n=36)$ compared to non-inflammatory precancerous lesions $(n=24)$. The tissue levels of MDA were higher but, with no significant difference in inflammatory bowel compared to non-inflammatory lesions (Table 2).

- Correlation analysis between the studied markers:

Significant positive correlation was noticed between TIGAR mRNA expression up regulation, and its protein expression $(\mathrm{r}=0.57, \mathrm{p}<0.0001)$. Also, TIGAR protein levels were significantly correlated with MDA ( $\mathrm{r}=0.27, \mathrm{p}=0.03)$ in CRC tissues.

Table 1: Analysis of the relation between TIGAR expression, TIGAR protein level, GSH and MDA level with the clinical-pathological characteristics of CRC cases

\begin{tabular}{|c|c|c|c|c|c|c|}
\hline \multicolumn{2}{|c|}{ Variables } & \multirow{2}{*}{\begin{tabular}{l|} 
No. \\
34 \\
26
\end{tabular}} & \multirow{2}{*}{\begin{tabular}{|c|}
$\begin{array}{c}\text { TIGAR } \\
\text { mRNA } \\
\text { expression }\end{array}$ \\
$\mathbf{4 . 1} \pm 0.3$ \\
$\mathbf{4 . 5} \pm 0.5$ \\
(N.S.)
\end{tabular}} & \multirow{2}{*}{\begin{tabular}{|c|} 
TIGAR \\
Protein level \\
(pg/mg tissue protein) \\
$6.3 \pm 0.4$ \\
$5.6 \pm 0.4$ \\
(N.S.)
\end{tabular}} & \multirow{2}{*}{$\begin{array}{c}\text { GSH } \\
\text { (mg/g tissue) }\end{array} \mid$} & \multirow{2}{*}{$\begin{array}{c}\text { MDA } \\
\text { (nmol/g tissue } \\
69.6 \pm 8.9 \\
72 \pm 3.4 \\
\text { (N.S.) }\end{array}$} \\
\hline Age & $\begin{array}{l}<\mathbf{5 0} \\
\geq \mathbf{5 0}\end{array}$ & & & & & \\
\hline Sex & $\begin{array}{l}\text { Male } \\
\text { Female }\end{array}$ & $\begin{array}{l}28 \\
32\end{array}$ & $\begin{array}{c}4.6 \pm 0.5 \\
4 \pm 0.3 \\
\text { (N.S.) }\end{array}$ & $\begin{array}{c}5.4 \pm 0.4 \\
6.5 \pm 0.4 \\
\text { (N.S.) }\end{array}$ & $\begin{array}{c}119.3 \pm 2.4 \\
126.2 \pm 2.5 \\
(p=0.03)\end{array}$ & $\begin{array}{c}69.6 \pm 3.6 \\
71.5 \pm 4 \\
\text { (N.S.) }\end{array}$ \\
\hline $\begin{array}{l}\text { Family } \\
\text { history }\end{array}$ & $\begin{array}{l}\text { Negative } \\
\text { Positive }\end{array}$ & $\begin{array}{c}54 \\
6\end{array}$ & $\begin{array}{c}4.3 \pm 0.3 \\
4.6 \pm 0.8 \\
\text { (N.S.) }\end{array}$ & $\begin{array}{c}6 \pm 0.3 \\
6.2 \pm 0.9 \\
\text { (N.S.) }\end{array}$ & $\begin{array}{c}124.1 \pm 1.7 \\
112.9 \pm 9.1 \\
\text { (N.S.) }\end{array}$ & $\begin{array}{c}70.5 \pm 2.8 \\
71.8 \pm 9.9 \\
\text { (N.S.) }\end{array}$ \\
\hline $\begin{array}{l}\text { Smoking } \\
\text { Status }\end{array}$ & $\begin{array}{l}\text { Smoker } \\
\text { Non-smoker }\end{array}$ & $\begin{array}{l}28 \\
32\end{array}$ & $\begin{array}{c}4.6 \pm 0.5 \\
4 \pm 0.3 \\
\text { (N.S.) }\end{array}$ & $\begin{array}{c}5.4 \pm 0.4 \\
6.5 \pm 0.4 \\
\text { (N.S.) }\end{array}$ & $\begin{array}{c}119.3 \pm 2.4 \\
126.2 \pm 2.5 \\
\text { (N.S.) }\end{array}$ & $\begin{array}{c}69.6 \pm 3.6 \\
71.5 \pm 4 \\
\text { (N.S.) }\end{array}$ \\
\hline $\begin{array}{c}\text { Lymph } \\
\text { node } \\
\text { metastasis }\end{array}$ & $\begin{array}{l}\text { Negative } \\
\text { Positive }\end{array}$ & $\begin{array}{l}28 \\
32\end{array}$ & $\begin{array}{c}3.1 \pm 0.3 \\
5.3 \pm 0.4 \\
(\mathrm{p}<0.0001)\end{array}$ & $\begin{array}{c}4.8 \pm 0.23 \\
7 \pm 0.4 \\
(p<0.0001)\end{array}$ & $\begin{array}{c}124.7 \pm 2.4 \\
121.9 \pm 2.6 \\
\text { (N.S.) }\end{array}$ & $\begin{array}{c}54.01 \pm 2.5 \\
85.14 \pm 2.6 \\
(p<0.0001)\end{array}$ \\
\hline Stage & $\begin{array}{l}\text { II } \\
\text { III }\end{array}$ & $\begin{array}{l}28 \\
32\end{array}$ & $\begin{array}{c}3.1 \pm 0.3 \\
5.3 \pm 0.4 \\
(p<0.0001)\end{array}$ & $\begin{array}{c}4.8 \pm 0.23 \\
7 \pm 0.4 \\
(p<0.0001)\end{array}$ & $\begin{array}{c}124.7 \pm 2.4 \\
121.9 \pm 2.6 \\
\text { (N.S.) }\end{array}$ & $\begin{array}{c}54.01 \pm 2.5 \\
85.14 \pm 2.6 \\
(p<0.0001)\end{array}$ \\
\hline Site & $\begin{array}{l}\text { Colon } \\
\text { Recto-sigmoid } \\
\text { Rectum }\end{array}$ & \begin{tabular}{c|}
32 \\
24 \\
4
\end{tabular} & $\begin{array}{c}4.54 \pm 0.4 \\
4 \pm 0.4 \\
4.1 \pm 1 \\
\text { (N.S.) }\end{array}$ & $\begin{array}{c}6.6 \pm 0.4 \\
5.1 \pm 0.4 \\
5.3 \pm 0.9 \\
(p=0.03) \\
\end{array}$ & $\begin{array}{c}124.3 \pm 2.5 \\
120.9 \pm 2.8 \\
125.1 \pm 8.7 \\
\text { (N.S.) }\end{array}$ & \begin{tabular}{c|}
$73 \pm 3.4$ \\
$67.3 \pm 4.3$ \\
$71.3 \pm 7.8$ \\
(N.S.) \\
\end{tabular} \\
\hline $\begin{array}{c}\text { Type } \\
\text { of tumor }\end{array}$ & $\begin{array}{l}\text { Adenocarcinoma } \\
\text { Mucoid } \\
\text { carcinoma } \\
\text { Signet ring } \\
\text { carcinoma }\end{array}$ & $\begin{array}{l}38 \\
12 \\
10\end{array}$ & $\begin{array}{l}4.4 \pm 0.4 \\
4.1 \pm 0.5 \\
\\
4.4 \pm 0.6 \\
\text { (N.S.) }\end{array}$ & $\begin{array}{c}6.1 \pm 0.4 \\
4.4 \pm 0.2 \\
\\
7.6 \pm 0.7 \\
(p=0.002)\end{array}$ & $\begin{array}{c}124.8 \pm 2.2 \\
117.3 \pm 4.7 \\
123.2 \pm 3.9 \\
\text { (N.S.) }\end{array}$ & $\begin{array}{c}70.9 \pm 3.4 \\
66.7 \pm 6.6 \\
74.1 \pm 6.1 \\
\text { (N.S.) }\end{array}$ \\
\hline
\end{tabular}

The table showed the relation of clinical features of CRC (colorectal cancer) patients and different measured markers. The results were expressed as mean $\pm \mathrm{SEM}, \mathrm{p} \leq 0.05$ is considered significant. T-test and Mann-Whitney test were used to compare the different markers with the clinical features of CRC patients (family history, lymph node metastasis, stage, and smoking status). Kruskal-Wallis test was used to compare the different markers with the site and type of tumor. N.S.: non-significant $\mathrm{p}$ value. 
Table 2: TIGAR expression, TIGAR protein levels, GSH and MDA levels in benign lesions.

\begin{tabular}{|c|c|c|c|}
\hline Variables & $\begin{array}{c}\text { Inflammatory bowel } \\
\text { diseases }(\mathbf{n}=\mathbf{3 6})\end{array}$ & $\begin{array}{c}\text { Non-inflammatory } \\
\text { precancerous lesions }(\mathbf{n}=\mathbf{2 4})\end{array}$ & P value \\
\hline TIGAR expression & $\mathbf{2 . 6 7} \pm \mathbf{0 . 2 2}$ & $\mathbf{2 . 1 9} \pm \mathbf{0 . 2 2}$ & $\mathbf{0 . 1 4}$ \\
\hline TIGAR protein level (ng/mg tissue protein) & $\mathbf{3 . 7 1} \pm \mathbf{0 . 2 8}$ & $\mathbf{3 . 3 6} \pm \mathbf{0 . 2 9}$ & $\mathbf{0 . 4 1}$ \\
\hline GSH levels (mg/g tissue) & $\mathbf{2 1 3 . 7 \pm 1 6 . 2 7}$ & $\mathbf{2 9 5 . 9 \pm 2 8 . 6 1}$ & $\mathbf{0 . 0 1}$ \\
\hline MDA levels (nmol/g tissue) & $\mathbf{6 0 . 8 6} \pm \mathbf{3 . 8 8}$ & $\mathbf{5 1 . 5 8} \pm \mathbf{2 . 7 3}$ & $\mathbf{0 . 0 8}$ \\
\hline
\end{tabular}

Benign lesions are classified into (Inflammatory bowel diseases and non-inflammatory precancerous lesions). The results were expressed as mean \pm SEM. Mann-Whitney test was used to compare both groups. P value is considered significant when $\leq 0.05$.

- Diagnostic utility of tissue levels of TIGAR mRNA expression and its protein as potential diagnostic biomarkers for CRC and benign colonic lesions:

At a cut-off point of 1.6 fold increase in TIGAR mRNA expression can differentiate between CRC patients and control group (an area under the curve (AUC) was $0.995, \mathrm{p}<0.0001$, the sensitivity of $93.3 \%$ and a specificity of $100 \%$ ). ROC curve for TIGAR protein levels also can discriminate between benign lesions and control tissues with an (AUC was $0.701, \mathrm{p}<0.0001$, sensitivity of $65.7 \%$ and specificity of 75\%). TIGAR protein levels can differentiate between CRC patients and benign group (an AUC was 0.821, p value $<0.0001$, with sensitivity of $91.7 \%$ and a specificity of $61.7 \%$ ) (Figure2).

(A)

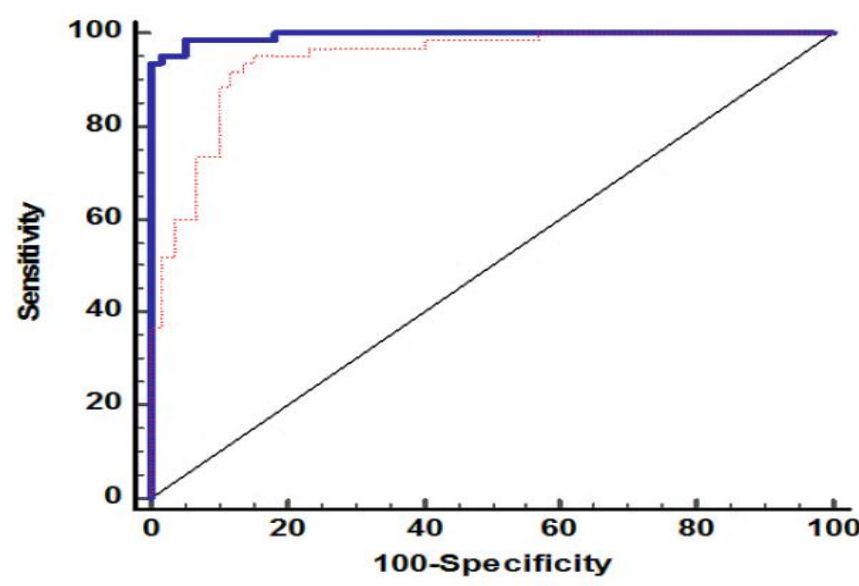

(C)

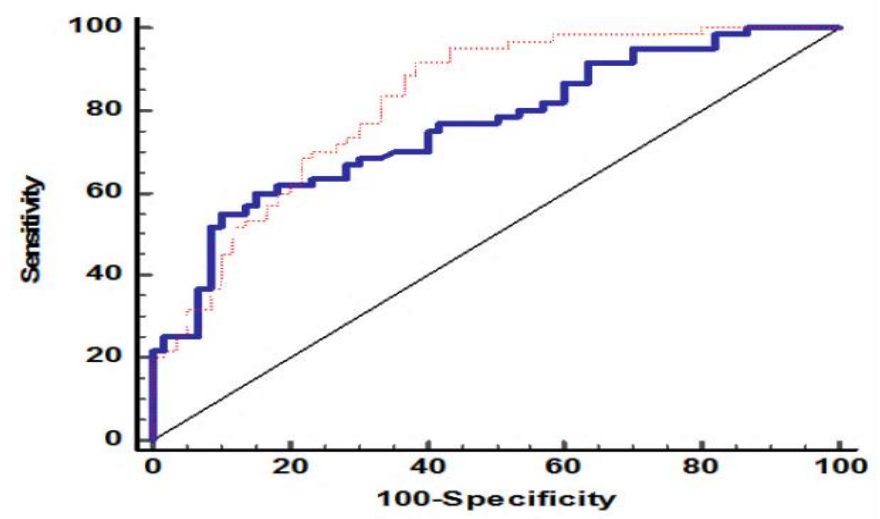

(B)

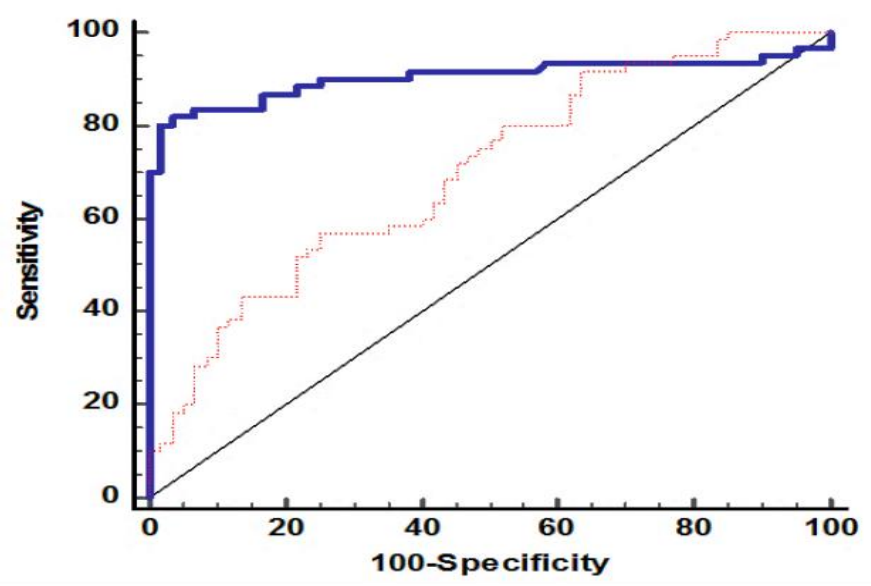

Figure (2): ROC curve analysis of TIGAR.

A: Using TIGAR mRNA expression and protein level for discriminating CRC tissues from control (cut-off point 1.6-fold, an area under the curve was 0.995 , p value $<0.0001$, the sensitivity of $93.3 \%$ and a specificity of $100 \%$ ) (Cutoff point $3.4 \mathrm{ng} / \mathrm{mg}$ tissue $\mathrm{pr}$, an area under the curve was 0.942 , p value $<0.0001$, the sensitivity of $93.3 \%$ and a specificity of $86.7 \%$ ) respectively.

B: Using TIGAR mRNA expression and protein level for discriminating benign lesions from control (cut-off point 1.2 -fold, an area under the curve was 0.903 , p value $<0.0001$, the sensitivity of $83.3 \%$ and a specificity of $95 \%$ ) (cut-off point $2.9 \mathrm{ng} / \mathrm{mg}$ tissue $\mathrm{pr}$, an area under the curve was 0.701 , $\mathrm{p}$ value $<0.0001$, the sensitivity of $65.7 \%$ and a specificity of $75 \%$ ) respectively.

C: Using TIGAR mRNA expression and protein level for discriminating CRC tissues from benign lesions (Cutoff point 3.9-fold, an area under the curve was 0.761 , p value $<0.0001$, the sensitivity of $55 \%$ and a specificity of 
90\%) (Cut-off point $3.6 \mathrm{ng} / \mathrm{mg}$ tissue pr, an area under the curve was 0.821 , p value $<0.0001$, the sensitivity of $91.7 \%$ and a specificity of $61.7 \%$ ) respectively.

\section{DISCUSSION}

Colorectal cancer (CRC) is a leading cause of mortality and morbidity worldwide ${ }^{(\mathbf{1 8}) .}$ Only $39 \%$ of CRC patients are diagnosed at early stages, as symptoms in this stage are nonspecific with the lack of enough screening tests ${ }^{(\mathbf{1 9})}$. The five years survival rate of CRC is around $60 \%$. ${ }^{(19)}$. Therefore, identifying patients at high risk, together with early diagnosis and understanding the molecular characterization of the primary tumor are important factors to outline prognostic and therapeutic targets ${ }^{(20)}$.

The current study showed that TIGAR was overexpressed in CRC tissues compared to control tissues and benign lesions at mRNA and protein levels. TIGAR gene expression and protein level were significantly upregulated in association with TNM staging, and presence of lymph node metastasis. These results agree with Al-Khayal et al. ${ }^{(9)}$ study who found that TIGAR mRNA and protein were significantly higher in stage II and III colorectal cancers compared to adjacent normal tissue. They also found highly expressed TIGAR protein in metastatic samples ${ }^{(9)}$.

Association of TIGAR with staging, metastasis and pathological nature of tumor suggests its role as an independent prognostic factor and therapeutic target in CRC. Most reported studies, showed increased expression of TIGAR mRNA and/or protein in solid tumor tissues or cells, which is indicating that higher TIGAR level are important for the survival and/or the proliferation of tumor cells (21)(22). The diagnostic criteria of the tissue TIGAR gene expression and protein level shown by ROC curve proved that they can be used in the diagnosis of CRC.

Colorectal adenoma is the most frequent precancerous lesion followed by chronic inflammatory bowel diseases (IBD), familial adenomatous polyposis and juvenile polyposis ${ }^{(23)}$. The established precancerous lesions of CRC give a better chance for earlier discovery with subsequent resection and decrease cancer development.

To the best of our knowledge this was the first study to assess the level of TIGAR in different benign bowel diseases. We reported a significant upregulation of TIGAR mRNA and protein level in benign lesions including adenoma, familial adenomatous polyposis, Crohn's disease, and ulcerative colitis in comparison with normal safety tissues. In agreement with the present findings Cheung et al. (11) reported overexpression of TIGAR in a model of ulcerative colitis as well as in adenomas. These data support the importance of TIGAR in proliferating tissue ${ }^{(\mathbf{1 1})}$.

Our results showed also that tissue TIGAR mRNA expression and protein level were elevated in inflammatory precancerous lesions than in noninflammatory precancerous lesions but with no significant difference. The diagnostic criteria of TIGAR
mRNA expression were studied by the ROC curve and showed that it can be used as a significant diagnostic marker for benign lesions.

Cancer development is triggered by oxidative stress caused by excessive production of reactive free radicals and impaired capacity to neutralize them. Malondialdehyde (MDA) is one of the most harmful products of lipid peroxidation (24). MDA has carcinogenic properties as it inhibit enzymes that guard against the destructive effects of oxidative stress ${ }^{(25)}$. In the gut, reactive oxygen species (ROS) mainly produced by mucosa and innate immune cells. In normal condition, intestinal ROS have bactericidal effects, participating in the intestinal defensive function (26). Reduced glutathione (GSH) and GSHdependent enzymes participate in the cellular defense against oxidative stress ${ }^{(27)}$.

In the current study, MDA level was significantly increased in CRC tissues in comparison with non-tumor tissues. This high MDA tissue level was significantly associated with TNM staging and positive lymph node metastasis in CRC cases. We also detected a significant positive correlation between tissue TIGAR protein levels with MDA in CRC tissues. The same results were documented by Maciejczyk et al. (28) where MDA levels were significantly elevated in CRC tissue in comparison with non-tumor tissues also, higher MDA levels were detected in patients with highgrade tumor and in subjects with lymph node metastases (28). Malondialdehyde can participate in malignant transformation connected with the colorectal invasion and tumor metastasis. It might therefore be used as a biomarker for clinical prognosis and has a potential role in CRC treatment ${ }^{(29)}$. The present results showed that MDA level was significantly higher in benign group than in the control group. This is in agreement with many studies that reported a high level of MDA in colitis and IBD ${ }^{(30,31)}$.

In addition, our results showed that GSH levels were significantly reduced in CRC tissues in comparison with non-tumor tissues and benign groups. These data are in accordance with the previous study done by Skrzydlewska et al. ${ }^{(32)}$ who found that GSH decreased in CRC tissue compared to normal tissues with more decrease in its level at late stage of cancer ${ }^{(32)}$. The present study showed that GSH level was higher in the benign group in comparison with controls and CRC groups. This may be explained as a sequence of increasing TIGAR expression in benign lesions tissue, which promotes an antioxidant response, helping the cells to survive transient on low levels of stress ${ }^{(10)}$. We also found that GSH levels were higher in the benign non-inflammatory group than in the inflammatory group.

The inflammatory reactions of IBD lead to release of free radicals from leukocytes and activated 
macrophages ${ }^{(33)}$. These activated immune cells reach the mucosa and enhance the production of large amounts of ROS that are potentially harmful and result in more inflammation and tissue injury, this was associated with decrease of antioxidant molecules. This imbalance of increased ROS triggers many of the clinical and pathophysiological features of IBD ${ }^{(33)}$. Such data indicate the importance of the GSH-system in the cellular defense mechanism against oxidative stress. Therefore, antioxidants might be a treatment modality of choice.

\section{CONCLUSION}

This current study showed the association between increased level of TIGAR expression and protein levels with the pathological types of CRC as well as increased oxidative stress in CRC patients. TIGAR gene and protein levels were also elevated in benign bowel lesions. Our results suggest the involvement of TIGAR in the pathogenesis of benign and malignant bowel diseases and could be a potential biomarker for their diagnosis. Therefore, targeting TIGAR may be considered as a promising therapeutic factor for management of benign bowel diseases and CRC.

Acknowledgments: We acknowledge the Assiut Medical School Grant Office.

Funding: This research has received a grant from: The Assiut Medical School Grant Office.

Conflicts of interest: There is no conflict of interest regarding all the authors.

\section{REFERENCES}

1. El-Bolkainy M (2013): Pathology of Cancer. (National Cancer Institute (NCI), Cairo University), Pp:250-261

2. Atef $\mathrm{N}$, Alieldin $\mathrm{N}$, Sherif $\mathrm{G}$ et al. (2020): Microsatellite instability and life style factors in sporadic colorectal cancer. Asian Pacific J. Cancer Prev., 21 (5): 1471-1480.

3. Schiedeck T , Matzel K (2017): colon cancer. in: Coloproctology, eds. Herold A, Matzel K E, Lehur P A, O'Connell P R) Springer Verlag Berlin Heidelberg, Pp: 289-302

4. Coghlin C, Murray G (2015): Biomarkers of colorectal cancer: Recent advances and future challenges. Proteomics - Clin. Appl., 9 (1): 64-71.

5. Tuohy T, Rowe K, Mineau G et al. (2014): Risk of colorectal cancer and adenomas in the families of patients with adenomas: A population-based study in Utah. Cancer, 120 (1): 35-42.

6. Giardiello F, Allen J, Axilbund J et al. (2014): Guidelines on genetic evaluation and management of lynch syndrome: A consensus statement by the us multi-society task force on colorectal cancer. Gastroenterology, 109 (8): 1159-79.

7. Ma H, Brosens L, Offerhaus G et al. (2018): Pathology and genetics of hereditary colorectal cancer. Pathology, 50 (1): 49-59
8. Conteduca V, Sansonno D, Russi S (2013): Precancerous colorectal lesions (Review). Int. J. Oncol., 43 (4): 973-984.

9. Al-Khayal K, Abdulla M, Al-Obeed $\mathrm{O}$ et al. (2016): Identification of the TP53-induced glycolysis and apoptosis regulator in various stages of colorectal cancer patients. Oncol. Rep., 35 (3): 1281-1286.

10. Yin N, , Xie T, Zhang H et al. (2020): IDH1-R132H mutation radiosensitizes U87MG glioma cells via epigenetic downregulation of TIGAR. Oncol. Lett., 19 (2): 1322-1330.

11. Cheung E, Athineos D, Lee $P$ et al. (2013): TIGAR is required for efficient intestinal regeneration and tumorigenesis. Dev. Cell, 25 (5): 463-477.

12. Ye L, Zhao X, Lu J et al. (2013): Knockdown of TIGAR by RNA interference induces apoptosis and autophagy in HepG2 hepatocellular carcinoma cells. Biochem. Biophys. Res. Commun., 437 (2): 300306.

13.Li Z, Shao Z, Chen S et al. (2020): TIGAR impedes compression-induced intervertebral disc degeneration by suppressing nucleus pulposus cell apoptosis and autophagy. J. Cell. Physiol., 235 (2): 1780-1794.

14. Sinha S, Ghildiyal R, Mehta V (2013): ATM$\mathrm{NF \kappa B}$ axis-driven TIGAR regulates sensitivity of glioma cells to radiomimetics in the presence of TNF $\alpha$. Cell Death Dis., 4 (2): e615.

15. Won K, Lim S, Kim G et al. (2012): Regulatory role of p53 in cancer metabolism via SCO2 and TIGAR in human breast cancer. Hum Pathol., 43 (2): 221228.

16. Ye L, Zhao X, Lu J et al. (2013): Knockdown of TIGAR by RNA interference induces apoptosis and autophagy in HepG2 hepatocellular carcinoma cells. Biochem. Biophys. Res. Commun., 437 (2):300-306.

17.Sun G, Sui X, Han D et al. (2017): TRIM59 promotes cell proliferation, migration and invasion in human hepatocellular carcinoma cells. Pharmazie, 72 (11): 674-679.

18. Favoriti P, Carbone G, Greco $M$ et al. (2016): Worldwide burden of colorectal cancer: a review. Updates Surg., 68 (1): 7-11.

19. Miyamoto Y, Hayashi N, Sakamoto Y et al. (2015): Predictors of long-term survival in patients with stage IV colorectal cancer with multi-organ metastases: a single-center retrospective analysis. Int. J. Clin. Oncol., 20: 1140-1146.

20. Wu W, Chen J, Wu J et al. (2017): Knockdown of tripartite motif-59 inhibits the malignant processes in human colorectal cancer cells. Oncol. Rep., 38 (4): 2480-2488.

21.Hong M, Zhu Y, Zhao $H$ et al. (2017): Overexpression of TIGAR predicts poor prognosis in elderly patients with cytogenetically normal acute myeloid leukemia ( CN-AML ), 10 (4): 4748-4755.

22.Lin L, Mi Y, Li X et al. (2019): Higher plasma concentration of TP53-induced glycolysis and apoptosis regulator is associated with a lower risk of colorectal cancer metastasis. Cancer Manag. Res., 11: 263-272.

23. Conteduca V, Sansonno D, Russi S et al. (2013): Precancerous colorectal lesions (Review). Int. J. Oncol., 43 (4): 973-984. 
24. Rašić I, Rašić A, Akšamija G, Radović S (2018): The relationship between serum level of malondialdehyde and progression of colorectal cancer. Acta Clin. Croat., 57 (3): 411-416.

25.Janion K, Szczepańska E, Nowakowska-Zajdel E et al. (2020): Selected Oxidative Stress Markers in Colorectal Cancer Patients in Relation to Primary Tumor Location-A Preliminary Research. Medicina (Kaunas), 56: 1-12.

26. Wang Z, Li S, Cao Y et al. (2016): Oxidative stress and carbonyl lesions in ulcerative colitis and associated colorectal cancer. https://doi.org/10.1155/2016/9875298

27. Baltruskeviciene E, Kazbariene B, Aleknavicius E et al. (2018): Changes of reduced glutathione and glutathione S-transferase levels in colorectal cancer patients undergoing treatment. Tumori., 104 (5): 375-380.

28. Maciejczyk M, Zar K, Koper-lenkiewicz O et al. (2020): Pro-Oxidant Enzymes, Redox Balance and Oxidative Damage to Proteins, Lipids and DNA in Colorectal Cancer Tissue. Is Oxidative Stress Dependent on Tumour Budding and Inflammatory
Infiltration? Cancers (Basel), 12 (6): 1636.

29. Cai F, Dupertuis Y, Pichard C (2012): Role of polyunsaturated fatty acids and lipid peroxidation on colorectal cancer risk and treatments. Curr. Opin. Clin. Nutr. Metab. Care, 15 (2): 99-106.

30. Achitei D, Ciobica A, Balan G et al. (2013): Different profile of peripheral antioxidant enzymes and lipid peroxidation in active and non-active inflammatory bowel disease patients. Dig. Dis. Sci., 58 (5): 1244-1249.

31.Vaghari T, Moein S, Qujeq D et al. (2017): Evaluation of the Potential Antioxidant Role of HighDensity Lipoprotein-Cholesterol (HDL-C) in Patients with Ulcerative Colitis. Ann. Color. Res., 5(3-4):e13699

32. Skrzydlewska E, Stanislaw S, Koda M et al. (2005): Lipid peroxidation and antioxidant status in preeclampsia. World J. Gastroentrology, 11 (3): 403406.

33. Pereira C, Magro F (2015): Oxidative Stress and DNA Damage: Implications in In fl ammatory. Inflamm Bowel Dis., 21 (10): 16-19. 